Check for updates

Cite this: Sustainable Energy Fuels, 2020, 4, 779

Received 10th June 2019

Accepted 25th November 2019

DOI: $10.1039 / \mathrm{c} 9 \mathrm{se} 00366 \mathrm{e}$

rsc.li/sustainable-energy

\section{Star-shaped triarylamine-based hole-transport materials in perovskite solar cells $\dagger$}

\author{
Rosinda Fuentes Pineda, ${ }^{a}$ Yaroslav Zems, ${ }^{\text {ac }}$ Joel Troughton, (1D b Muhammad R. Niazi, ${ }^{\mathrm{c}}$ \\ Dmitrii F. Perepichka, (D)*c Trystan Watson (D)*b and Neil Robertson (D)*a
}

\begin{abstract}
Two novel star-shaped triarylamine-based hole transport materials with triphenylamine (STR1), or a partially oxygen-bridged triphenylamine (STRO), as core and para-substituted triphenylamine side arms were synthesized, fully characterized and studied in perovskite solar cells. Their thermal, optical, electrochemical and charge transport properties were examined and compared in the context of their molecular structure. Due to its more planar configuration, STRO showed a red-shifted absorption in comparison with STR1. STRO also forms a more stable amorphous glassy state and showed higher glass transition temperature than STR1 and spiro-OMeTAD. These HTMs were tested in perovskite solar cells using a device configuration of $\mathrm{FTO} / \mathrm{bl}-\mathrm{TiO}_{2} / \mathrm{mp}-\mathrm{TiO}_{2} / \mathrm{CH}_{3} \mathrm{NH}_{3} \mathrm{Pbl} / \mathrm{HTM} / \mathrm{Au}$ showing a power conversion efficiency of $13.3 \%$ for STRO and $11.5 \%$ for STR1. The STRO-based devices showed higher fill factor and better reproducibility than spiro-OMeTAD-based cells. Without dopant additives, solar cells based on STRO exhibited a good photocurrent density of $16.63 \mathrm{~mA} \mathrm{~cm}{ }^{-2}$ and the efficiency improved from a starting PCE of $3.9 \%$ to $6.6 \%$ after two weeks of storage.
\end{abstract}

\section{Introduction}

Perovskite solar cells (PSCs) have revolutionized the photovoltaic field having shown rapid development in their power conversion efficiencies (PCEs), from the initial value of 3.8\% demonstrated by Miyasaka ${ }^{1}$ in 2009 to a current certified PCE of $25.2 \%$ for single rigid perovskite cell and $28.0 \%$ for perovskite/Si tandem cell. ${ }^{2}$ The rapid improvement is primarily due to the unique properties of the perovskite material $\mathrm{APbX}_{3}\left(\mathrm{~A}=\mathrm{CH}_{3} \mathrm{NH}^{3+}\right.$ (methylammonium, $\left.\mathrm{MA}\right)$ or $\mathrm{CH}_{3}\left(\mathrm{NH}_{2}\right)^{2+}$ (formamidinium, $\mathrm{FA}$ ); $\mathrm{X}=\mathrm{Cl}^{-}, \mathrm{Br}^{-}, \mathrm{I}^{-}$or mixed halides) including large absorption coefficient, long carrier diffusion length, small exciton binding energy and high charge carrier mobility. ${ }^{3,4}$ To date, the best performing perovskite solar cell comprises a sandwich architecture in which the perovskite absorber is embedded between an electron transport layer (ETL) and a hole transport layer (HTL). The hole transport material (HTM) plays a critical role in the mechanism and stability of high-efficiency PSCs. The HTM extracts the photogenerated holes from the perovskite and transports them to the back-contact metal electrode

${ }^{a}$ EaStCHEM School of Chemistry, The University of Edinburgh, King's Buildings, David Brewster Road, Edinburgh,EH9 3FJ, UK. E-mail: neil.robertson@ed.ac.uk

${ }^{b}$ Swansea University Bay Campus, Fabian Way, Swansea, SA1 8EN, UK. E-mail: T.M. Watson@swansea.ac.uk

'McGill University, Montreal, Quebec, Canada

$\dagger$ Electronic supplementary information (ESI) available: Synthetic procedures, NMR spectra, thermal properties, solar cell characteristics, water contact angle. See DOI: $10.1039 /$ c9se00366e improving the hole transfer efficiency. The HTL also serves as an energetic barrier between the electrode and the perovskite layer minimising charge recombination at the interface which leads to better device performance..$^{5-7}$ Moreover, the HTM helps to reduce the degradation of the device by protecting the sensitive perovskite from the diffusion of the metal electrode into the perovskite layer as well as from air and moisture. ${ }^{6,8,9}$ The structure and properties of the HTM are crucial to achieve efficient and stable solar cells. ${ }^{10,11}$ Hence, a wide number of alternative HTMs structures has been investigated in PSCs including inorganic materials, ${ }^{12-14}$ small organic molecules $^{15-17}$ and polymers. ${ }^{18-20}$

Among all the molecular motifs used for HTMs, triphenylamines (TPAs) are one of the most promising candidates. To date, TPA-based materials like 2,2,7,7'-tetrakis( $N, N$-di- $p$ methoxyphenylamine)-9,9'-spirobifluorene (spiro-OMeTAD) ${ }^{21,22}$ and poly[bis(4-phenyl)(2,4,6-trimethylphenyl)amine] (PTAA) ${ }^{23,24}$ are the most popular and best performing HTMs in PSCs. Nevertheless, they are relatively expensive and have been demonstrated to hinder the stability of the device. ${ }^{25-30}$ Triphenylamines are good electron donors due to the easy oxidation of the nitrogen centre and their capacity to transport positive charges via radical cations. ${ }^{31,32}$ Accordingly, TPA units have been used to build a wide variety of both small molecules and polymers. ${ }^{9,31-34}$

Polymeric materials (such as the abovementioned PTAA) have been demonstrated as good candidates for HTMs, offering relatively high conductivities and mobilities, excellent morphological and thermal stability and high device 
efficiencies. ${ }^{19,31,33,35}$ Furthermore, the hydrophobic nature of most polymers may serve as protection for the perovskite film to humidity which may improve the stability of the device. ${ }^{27,36-38}$ Nevertheless, polymeric HTMs suffer from complicated synthesis and purification routes as well as batch-to-batch molecular weight variation which can significantly affect the material properties and consequently the device performance and reproducibility. ${ }^{\mathbf{1 1 , 3 5 , 3 9 , 4 0}}$ In contrast, small organic molecules present a well-defined molecular weight, easier rational tuning of the properties (such as morphological, thermal, optoelectronic, etc.) and usually the synthesis, purification and device fabrication of small organic molecules are more reproducible, making them more suitable candidates for upscaling and industrial application. ${ }^{11,17,35}$

Star-shaped molecules are a group of small organic molecules containing a central aromatic core with multiple functional units attached to the core. Due to their unique chemical structure, these materials not only show characteristic properties of small organic molecules but also present properties of polymeric materials i.e. combining well-defined structures and physical properties, high thermal stability, good solubility and good film forming properties. ${ }^{\mathbf{4 1 , 4 2}}$ These materials have been widely used in organic field effect transistors (OFET), ${ }^{\mathbf{4 3 , 4 4}}$ organic light-emitting diodes (OLEDs) ${ }^{45}$ and organic solar cells. $^{46}$ More recently there have been some reported starshaped molecules as HTMs in PSCs. ${ }^{47-49}$ In this context, the use of fused aromatic rings with heteroatoms is of interest in the design of HTMs because of an increase in the rigidity and coplanarity of the molecules and maximization of overlap of the $\pi$-orbitals which favours the face-to-face $\pi$-stacking facilitating intermolecular charge transport. ${ }^{50}$ In previous studies, Hyeju $\mathrm{Choi}^{47}$ and collaborators reported a starshaped hole transport material with a planar central amine, coded as OMeTPA-FA and compared this with the non-planar structure. The planar structure showed better charge separation and higher hole mobility which resulted in an overall PCE of $13.6 \%$. Some conceptually-related work has also been carried out for dimers; Wakamiya ${ }^{50}$ and colleagues studied the properties of partially bridged triphenylamine dimers as hole transport materials. These compounds formed a pi-stacking arrangement in their crystal structure which leads to high carrier mobilities. Given the potential to combine attractive features of both small-molecules and polymer materials, further exploration of star-shaped molecules as HTMs in PSC is a promising area for study.

In this work, we report two new star-shaped hole transport materials labelled as STR1 and STR0. These molecules contain a central TPA unit and three TPA units in the periphery linked to the core by an acetylene bridge. In STR0, we incorporate a partially oxygen-bridged TPA as the central unit of the starshaped structure. This results in a quasi-planar structure where the phenyl groups of the central TPA are constrained by two oxygen bridges. The chemical structures of STR1 and STR0 are shown in Fig. 1. The comparison of these materials illustrates the role of increasing the planarity and lowering the symmetry of STR0 compared with STR1.

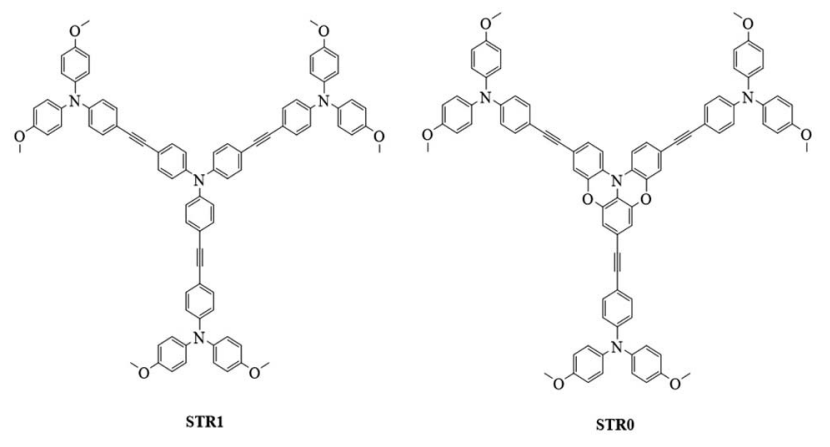

Fig. 1 Chemical structure of STR1 and STRO.

\section{Results and discussion}

The complete synthetic route and detailed experimental procedure are described in the ESI (Scheme S1 $\dagger$ ). The compound 3 (4-ethynyl- $N, N$-bis(4-methoxyphenyl)aniline) was synthesized by a similar route to the one we described previously. ${ }^{51}$ Triphenylamine (1a) was brominated with $n$-bromosuccinimide (NBS) to give $\mathbf{1}$ in an analogous procedure to that previously reported by Guanglong Wu. ${ }^{52}$ STR1 was prepared via a Sonogashira coupling ${ }^{53,54}$ reaction using $\mathrm{PdCl}_{2}\left(\mathrm{PPh}_{3}\right)_{2}, \mathrm{CuI}$ and $\mathrm{PPh}_{3}$ in toluene in the presence of piperidine at $90{ }^{\circ} \mathrm{C}$. On the other hand, for the synthesis of STR0, 2,2':6, $2^{\prime \prime}$-dioxytriphenylamine (DOT) was prepared in a comparable route to the one reported by Kuratsu ${ }^{55-57}$ with some modifications described in detail in the ESI. $\dagger$ DOT was later brominated with pyridinium bromide perbromide. Finally, a Sonogashira coupling reaction was performed to afford STR0 as the final product. The analytical and spectroscopic data for both HTMs are consistent with the formulated structures.

The optical properties of the two HTMs were investigated by UV/Vis and photoluminescence (PL) spectroscopy in dichloromethane (DCM) solutions. Additionally, molar extinction coefficients were calculated for each compound using the LambertBeer law and the results are summarized in Table 1. The strongest absorption peaks (solid line, Fig. 2, left) of STR1 and STR0 were observed at $392 \mathrm{~nm}$ and $419 \mathrm{~nm}$, respectively, which leads to weak absorption in most of the visible region. The $\lambda_{\mathrm{abs}}$ of STR0 is more red shifted than that of STR1. The emission spectra (dashed line, Fig. 2a) of STR1 and STR0 show an emission centred at $454 \mathrm{~nm}$ and $464 \mathrm{~nm}$ respectively, with a larger Stokes shift indicating that STR1 presents more conformational change in the excited state in comparison with STR0. The redshift and greater rigidity of STR0 can be explained by the more planar configuration of the central triarylamine due to small torsion angle of the phenyl units and the more delocalized $\pi$-conjugation which reduces the energy gap between HOMO (highest occupied molecular orbital) and LUMO (lowest unoccupied molecular orbital). The electrochemical properties of both HTMs were investigated by square-wave voltammetry (SWV) using ferrocene/ferrocenium $\left(\mathrm{Fc} / \mathrm{Fc}^{+}\right)$as the internal standard. The HOMO energy levels were evaluated from the SWV data (Fig. 2b) on the basis of the equation $E_{\text {Hомо }}=-5.1-$ 
Table 1 Summary of the optical, electrochemical, charge transport and thermal properties

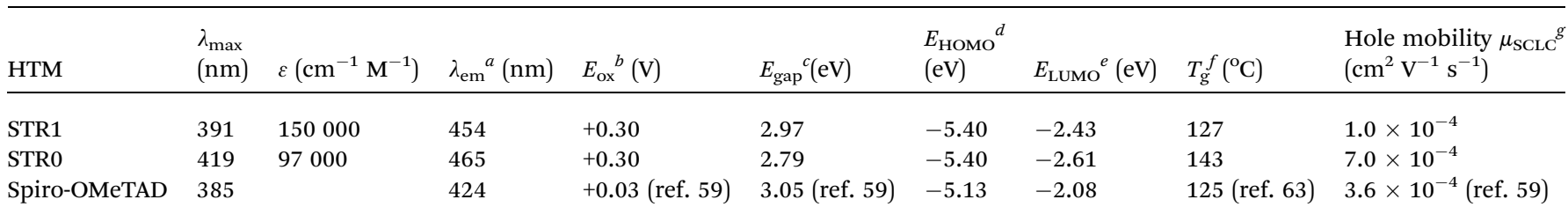

${ }^{a}$ Excitation at $\lambda_{\max } \cdot{ }^{b}$ From SWV and CV measurements and referenced to ferrocene/ferrocenium. ${ }^{c}$ Optical gap determined from the intersection of the excitation and emission spectra. ${ }^{d} E_{\mathrm{HOMO}}(\mathrm{eV})=-5.1-\left(E_{\mathrm{Ox}}\right) \cdot{ }^{e} E_{\mathrm{LUMO}}=E_{\mathrm{HOMO}}+E_{\text {gap }} \cdot{ }^{f}$ Determined from differential scanning calorimetry (DSC). ${ }^{g}$ Estimated from SCLC measurements.

$\left(E_{\mathrm{ox}}\right)$, where $E_{\mathrm{ox}}$ is the oxidation potential of the HTM with reference to ferrocene. ${ }^{58}$ The HOMO energy levels of both HTMs were estimated at $-5.40 \mathrm{eV}$ which is clearly lower than that of spiro-OMeTAD $(-5.14 \mathrm{eV}){ }^{59,60}$

Density functional theory (DFT) at B3LYP/6-31G(d) level was used to predict the electronic properties of STR1 and STR0. The HOMO and LUMO of the optimized structures are shown in Fig. 3. The HOMO is delocalized mainly over the $\pi$ orbitals of the central triphenylamine core, the acetylene bridge and the adjacent aromatic rings of the peripheral units. The LUMO is located over part of two of the peripheral triphenylamine units and it is extended to part of the triphenylamine core. The calculated HOMO energy values of STR1 $(-4.6 \mathrm{eV})$ and STR0 $(-4.6 \mathrm{eV})$ are similar which is consistent with the electrochemical results. Overall these results indicate that the hole transfer from $\mathrm{CH}_{3} \mathrm{NH}_{3} \mathrm{Pbl}_{3}(-5.4 \mathrm{eV})$ to the new HTMs is energetically favourable. Also, extension of the HOMO over the majority of the molecule should favour good intermolecular HOMO-HOMO interaction to favour effective hole transport.

The hole mobilities were determined by SCLC (space charge limited current) measurements in a hole-only device of configuration ( $\mathrm{Si} / \mathrm{SiO}_{2} / \mathrm{Au} / \mathrm{PEDOT}$ :PSS(Al 4083)/HTL/ $/ \mathrm{MoO}_{3} / \mathrm{Ag}$ ). The device fabrication and measurement details are described in the experimental section. Fig. 4 shows the $J-V$ curves for the hole-only devices at room temperature. The curves show three regions: ohmic conduction (with slope $\sim 1$ ) at low applied bias,
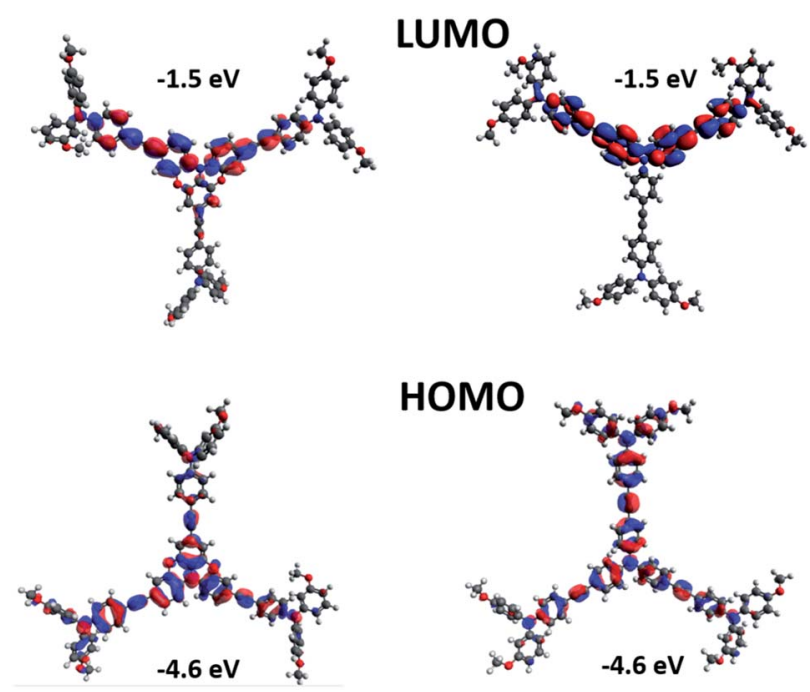

Fig. 3 Molecular orbital distribution of $\mathrm{HOMO}$ and LUMO of STR1 and STRO at B3LYP/6-31G(d)level of theory.

a trap-filled region (with slope $>2$ ) at higher voltages where all the defects states are occupied by the charge carriers, and the SCLC region (with slope $\sim 2$ ). The mobilities were calculated using the Mott-Gurney equation from SCLC regime, assuming ohmic contacts using a procedure previously reported. ${ }^{61}$ The
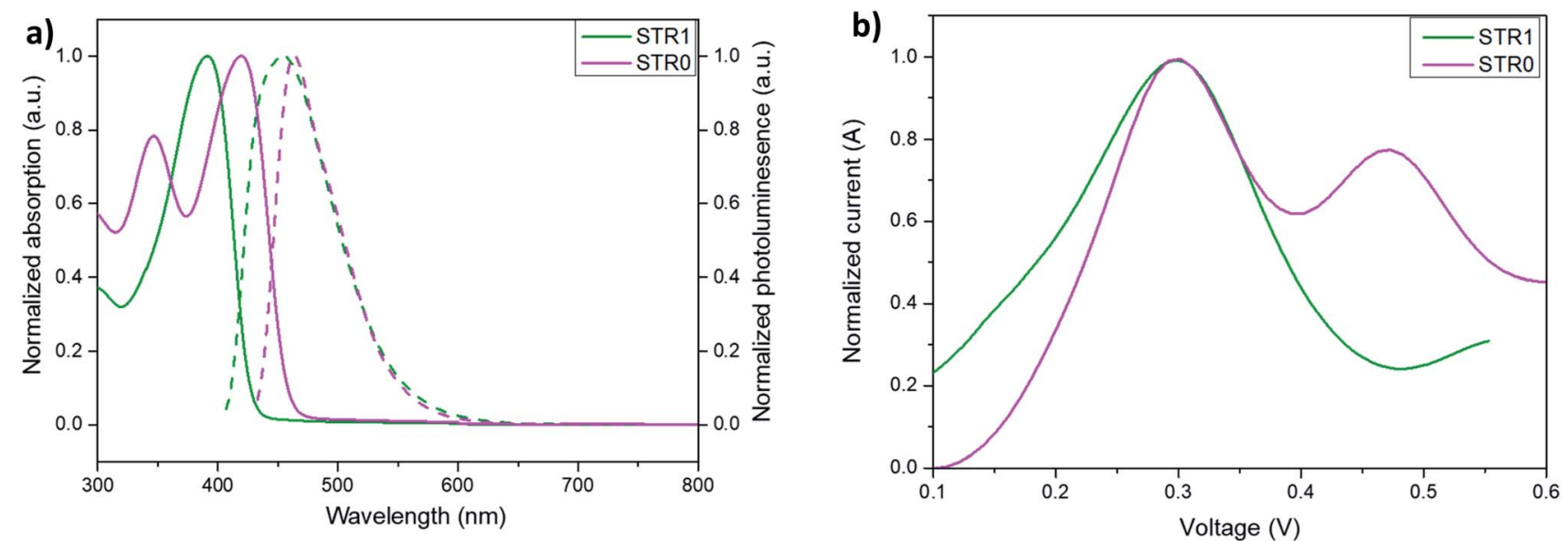

Fig. 2 (a) Normalized UV-Vis absorption (solid line) and emission (dashed line) of each HTM, (b) square-wave voltammetry of STR1 (green line) and STRO (pink line). 


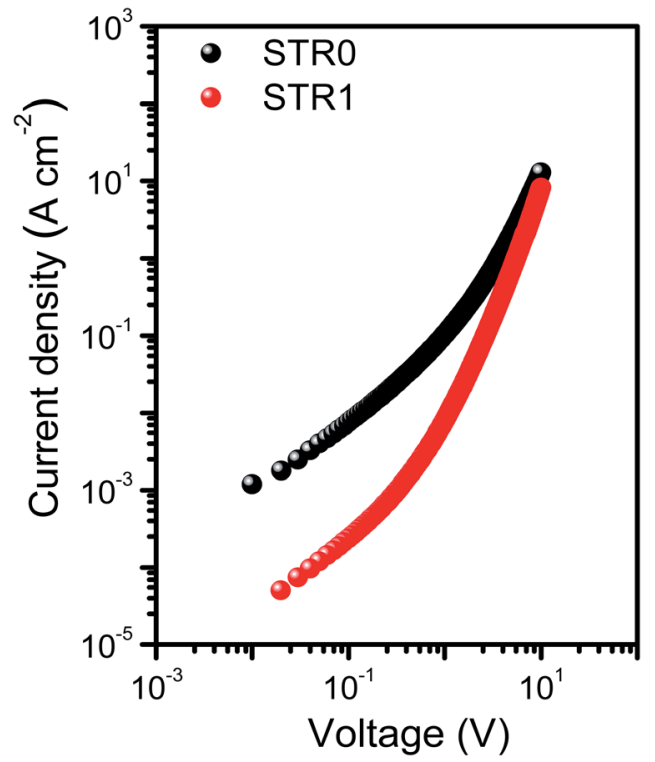

Fig. 4 Space charge limited current measurements with undoped STR1 and STRO in the device configuration $\mathrm{Si} / \mathrm{SiO}_{2} / \mathrm{Au} / \mathrm{PEDOT}$ :PSS(Al 4083)/HTL/ $\mathrm{MOO}_{3} / \mathrm{Ag}$.

results (Table 1) show both compounds to have hole mobilities broadly comparable with spire-OMeTAD, with slightly higher value for STR0, attributed to the more planar structure that may lead to better pi-stacking.

We evaluated the thermal properties of the HTMs by differential scanning calorimetry (DSC) and the results can be found in the ESI (Fig. S1 $\dagger$ ). The DSC data showed glass transition temperatures $\left(T_{\mathrm{g}}\right)$ of $127^{\circ} \mathrm{C}$ for STR1 and $143^{\circ} \mathrm{C}$ for STR0 which are higher than that of Spiro-OMeTAD $\left(125^{\circ} \mathrm{C}\right) .{ }^{62}$ These results confirm that STR1 and STR0 form stable amorphous glasses and have good thermal stability. A summary of the optical, electrochemical, charge transport and thermal properties of the HTMs is depicted in Table 1.

To investigate the performance of STR0 and STR1 as HTMs, a set of perovskite solar cells was fabricated. For comparative analysis and reference, devices based on doped spiro-OMeTAD as HTM were also fabricated. The HTMs were all doped using identical steps and similar concentration of additives, as is described in the experimental section. The device architecture adopted for these studies was $\mathrm{FTO} / \mathrm{bl}-\mathrm{TiO}_{2} / \mathrm{mp}-\mathrm{TiO}_{2} / \mathrm{CH}_{3} \mathrm{NH}_{3}$ $\mathrm{PbI}_{3} / \mathrm{HTM} / \mathrm{Au}$ as depicted in Fig. 5c. For reliable comparative analysis, all devices were fabricated in a single continuous study over 8 repeat cells for STR1 and STR0 and 16 repeat devices for spiro-OMeTAD. Fig. 5a shows the photocurrent density-voltage $(J-V)$ curves measured immediately after device fabrication and the table in the inset gives the corresponding photovoltaic parameters of the best-performing solar cells. The best devices with doped STR0 and STR1 show PCEs of 13.3\% and 11.5\%, respectively, whereas $15.2 \%$ was obtained with doped spiroOMeTAD. Considering that spiro-OMeTAD has been extensively studied and optimised as HTMs for many years, these initial results show promising application potential of the new HTMs in high efficiency perovskite solar cells. Fig. 6 shows the box plots with the mean and standard deviation of the solar cell parameters measured after fabrication and the results are summarised in Table S1 (ESI $\dagger$ ). The cells also show some hysteresis consistent with typical behaviour for cells of this geometry (Fig. S2 $\dagger$ ). Fig. 5b shows the EQE spectra and corresponding integrated $J_{\text {sc }}$ values of PSCs with STR0, STR1, and spiro-OMeTAD. Devices based on STR1 and spiro-OMeTAD show enhanced EQE values in comparison to those based on STR0. The $J_{\mathrm{sc}}$ values and trend are similar to the integrated values obtained from the EQE spectra. The lower $J_{\text {sc }}$ of the new HTMs in comparison with spiro-OMeTAD might possibly be attributed to the deeper HOMO energy levels which lowers the driving force for charge injection, due to the smaller difference in the energy levels between the valence band of $\mathrm{CH}_{3} \mathrm{NH}_{3} \mathrm{PbI}_{3}$ and the HOMO of the HTMs. ${ }^{24,63}$ The higher $J_{\mathrm{sc}}$ value for spiro-MeOTAD however, may also arise from an optimised dopant regime in comparison with our new HTMs. It has been shown in previous studies that devices with intrinsic, undoped, spiro-OMeTAD present low $J_{\mathrm{sc}}$ and FF and high series resistance $\left(R_{\mathrm{S}}\right)$. The poor conductivity of spiro-MeOTAD causes the high $R_{\mathrm{s}}$ due to deficient charge transport which results in poor charge collection and high charge recombination. In contrast, a)

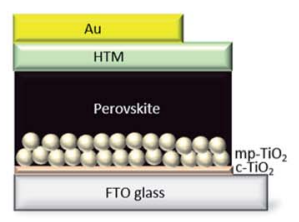

b)

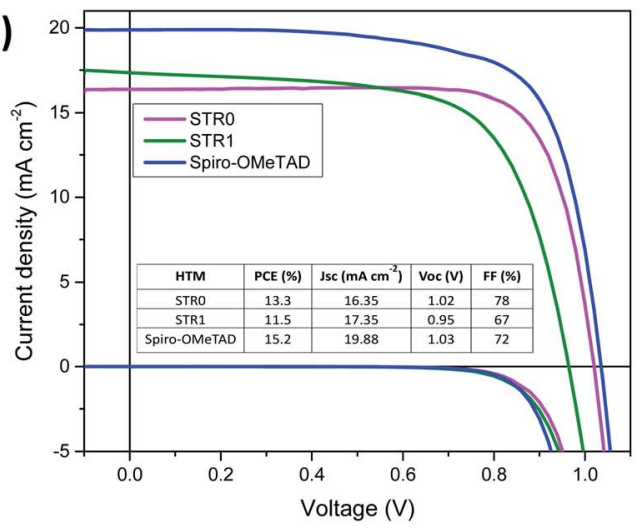

c)

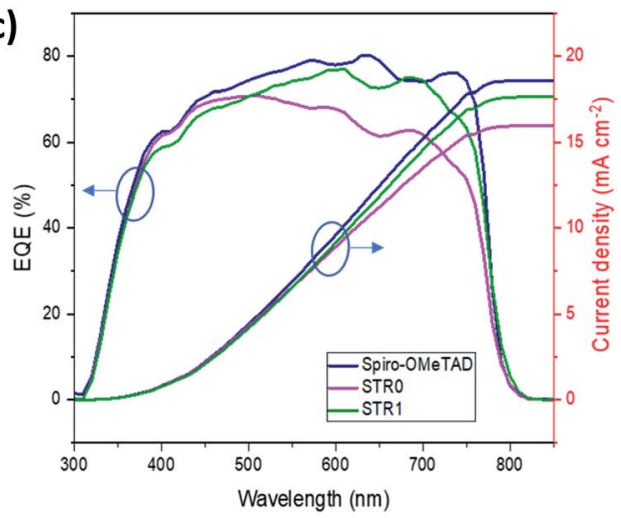

Fig. 5 (a) Device structure in the configuration $\mathrm{FTO} / \mathrm{bl}-\mathrm{TiO}_{2} / \mathrm{mp}-\mathrm{TiO}_{2} / \mathrm{CH}_{3} \mathrm{NH}_{3} \mathrm{Pbl}_{3} / \mathrm{HTM} / \mathrm{Au}$, (b) J-V curves of the champion PSCs with STR1, STRO and spiro-MeOTAD as HTMs measured after fabrication. (c) EQE spectra and integrated current density of devices with STRO, STR1 and spiro-OMeTAD. 

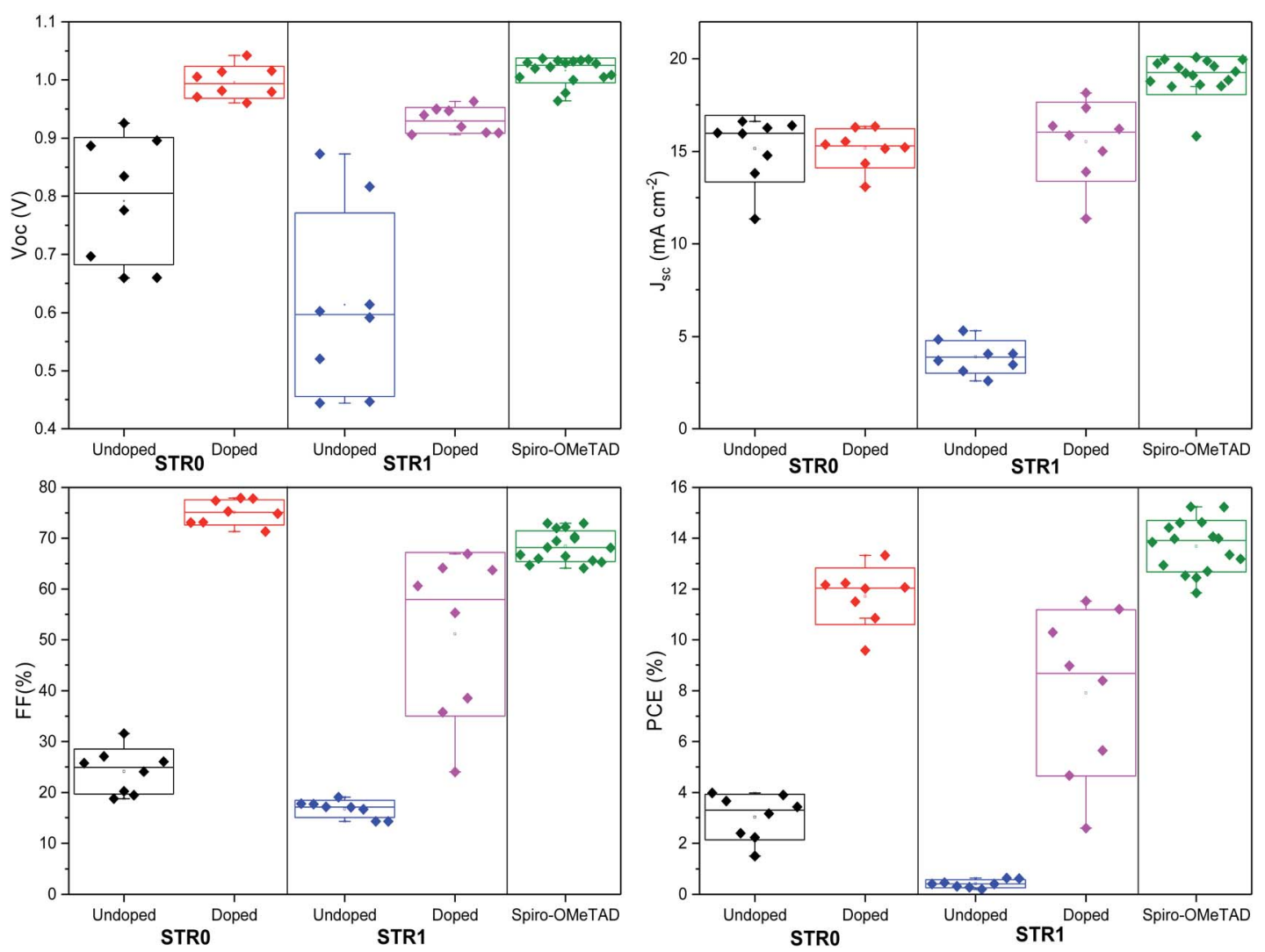

Fig. 6 Box plot of photovoltaic parameters of PSCs with STR1, STRO and spiro-OMeTAD measured after fabrication.

upon addition of dopants a significant increase in $J_{\mathrm{sc}}$ and $\mathrm{FF}$ is observed as a result of the increased conductivity and charge transport of spiro-OMeTAD. ${ }^{64,65}$ There has been numerous studies to understand and optimize the additives for spiro-OMeTAD. ${ }^{64-72}$ Even small changes in the type and/or concentration of additives can result in big differences in the photovoltaic parameters. ${ }^{65-67,72}$ For instance, it has been shown that in general conductivity increases by several orders of magnitude as the doping concentration increases due to a decrease of the trap states, and then stabilises or decreases at higher concentrations. ${ }^{66}$ Therefore, an optimised doping regime for the new HTMs could lead to significant improvements to the photovoltaic parameters. Interestingly, doped STR0 and STR1 showed a higher water contact angle than similarly-doped spiro-OMeTAD (Fig. S4†), which suggests the former might be able to provide better protection of the perovskite layer from moisture in a cell.

The $V_{\text {oc }}$ values of cells with the new HTMs are comparable with that of spiro-OMeTAD. Although in general, deeper HOMO energy levels are related to higher $V_{\mathrm{oc}}$, there have been some studies demonstrating that the energetics of the HTM is not the only factor limiting the $V_{\mathrm{oc}}$ in photovoltaic devices but it is rather a combination of various factors such as different recombination paths, fabrication process, and effect on the properties and morphology of the HTM and the perovskite layer. ${ }^{73-76}$ For instance, as demonstrated by Gelmetti and coworkers $^{75}$ the HOMO energy of the HTMs can be different when deposited on top of the perovskite layer than the value obtained from the electrochemical properties. Hence, it has been suggested that rather than tuning the energy levels, a more proper way to improve $V_{\mathrm{oc}}$ values is through minimising charge recombination, improving material processing and doping.

The box plots (Fig. 6) shows the reproducibility of the solar cells parameters. The data indicate a good device reproducibility in particular for STR0 and spiro-OMeTAD which show small standard deviation values in all the photovoltaic parameters. The fill factor provides information about the quality of the solar cells and usually high values indicate low series resistance, good interfacial morphology and high charge transport and uniform films. The significantly higher FF obtained with STR0 in comparison with STR1 and spiro-OMeTAD can be the result of the higher hole mobility (Table 1). Moreover, the close distribution of the $J_{\mathrm{sc}}, V_{\mathrm{oc}}$ and PCE values also give a hint of the good homogeneity of the films.

Solar cells using undoped STR1 and STR0 as HTM were also fabricated for comparative analysis. In general, when STR0 and STR1 are used with dopants, the performance of the PSCs exhibits a noticeable enhancement similar to many other HTMs. ${ }^{77-79}$ Nevertheless, it was observed that STR0-based devices afford a noteworthy maximum $J_{\mathrm{sc}}$ of $16.63 \mathrm{~mA} \mathrm{~cm}^{-2}$ and a close distribution of the device parameters without the presence of additives. This high $J_{\mathrm{sc}}$ value can be attributed to comparatively good charge transport and a homogeneous film in the device.

Furthermore, to compare the stability of the solar cells with STR0, STR1 and spiro-OMeTAD, the devices were tested after two 
weeks of storage in a nitrogen glove box at room temperature without encapsulation. These results are shown in the box plot in Fig. S $3 \uparrow$ and the extracted average values with the corresponding standard deviation are summarised in Table S2. $\dagger$ After two weeks, devices based on doped STR0 and STR1 exhibited a decrease of the photovoltaic parameters, but similar distribution of the photovoltaic parameters. For spiro-OMeTAD, devices showed an increase in the FF. However, on average the photovoltaic parameters for spiro-OMeTAD also decreased. Also noticeable is the increase in the standard deviation of the fill factor which results in lower reproducibility. For undoped HTMs, devices with STR1 presented a small increase in the device performance due to an increase of both $V_{\text {oc }}$ and $J_{\text {sc }}$. More importantly, there is a noticeable improvement of the device performance with undoped STR0. After two weeks, undoped STR0-based solar cells afford a maximum PCE value of $6.6 \%$ in comparison with an initial value of $4 \%$. Since, most common dopants used for spiroOMeTAD are hygroscopic which can degrade the perovskite layer in the device configuration, these results indicate that STR0 could possibly use lower dopant concentration or different dopants which would ultimately result in a better device stability.

\section{Conclusions}

In summary, we have reported the synthesis and characterisation of two novel triphenylamine-based starshaped hole transporting materials in perovskite solar cells. The structures contain a partially oxygen bridged triphenylamine (STR0) and a triphenylamine moiety (STR1) as the core units with three triphenylamine units in the periphery. The new HTMs exhibited excellent optoelectronic, electrochemical, charge transport and thermal properties for application in PSCs. Promisingly, this first study of solar cells with doped STR0 and STR1 as HTMs afford efficiencies of $13.32 \%$ and $11.52 \%$. Overall, STR0 showed remarkably high fill factor in comparison with spiro-OMeTAD which can be attribute to the better and more stable amorphous character, resulting in a more homogeneous film sustained by its higher glass transition temperature $\left(145^{\circ} \mathrm{C}\right)$. The lower symmetry of STR0 over STR1, may play an important role in the formation and stabilisation of the amorphous film, while the increased planarity maintains good hole-transport behaviour. Furthermore, the high $J_{\mathrm{sc}}$ value in devices with undoped STR0 may indicate that lower dopant concentration is required which could increase the stability of the devices. Further optimisation of dopants, doping concentration and processing procedures for both materials may perhaps enhance the device performance. These results should encourage further consideration in particular of star shaped, rigid-geometry molecules such as STR0 as very good candidates for high efficiency and stable perovskite solar cells.

\section{Experimental details}

\subsection{Materials and synthesis}

All reagents were purchased from either Sigma-Aldrich or AlfaAesar and they were used as received without further purification unless otherwise stated.

\subsection{Chemical characterization}

${ }^{1} \mathrm{H}$ and ${ }^{13} \mathrm{C}$ NMR spectra were recorded on a Brucker Advance 500 spectrometer $\left(500 \mathrm{MHz}\right.$ for ${ }^{1} \mathrm{H}$ and $124 \mathrm{MHz}$ for ${ }^{13} \mathrm{C}$ ). The deuterated solvents are indicated in the synthesis description. Chemical shifts, $\delta$, are given in ppm, using the solvent residual as an internal standard. MS were recorded on Bruker ESI MicroTof equipped with LC using electrospray ionization (ESI). Elemental analyses were carried out by Stephen Boyer at London Metropolitan University.

\subsection{Synthesis and characterisation}

STR1. A mixture of tris (4-bromophenyl) amine $(2.07 \mathrm{mmol}$, $1 \mathrm{~g}$ ), (PPh3)2PdCl2 (0.456 mmol, $0.29 \mathrm{~g}$ ), CuI (0.09 mmol, 16 $\mathrm{mg}$ ), PPh3 (0.414 mmol, $0.108 \mathrm{~g}$ ) and piperidine $(30 \mathrm{~mL})$ in toluene $(20 \mathrm{~mL})$ were stirred and degassed for one hour. A degassed solution of 4-ethynyl- $N, N$-bis(4-methoxyphenyl) aniline was added drop-wise over 5 hours at $100{ }^{\circ} \mathrm{C}$ under nitrogen atmosphere and the mixture stirred for 12 under the same conditions. The reaction was stopped by the addition $20 \mathrm{~mL}$ of $\mathrm{NH}_{4} \mathrm{Cl}$ and washed with a $10 \%$ solution $\mathrm{HCl}$ and $10 \%$ solution $\mathrm{KOH}$. The crude was passed through a quick silica plug in DCM and the product purified by column chromatography ( $\mathrm{SiO} 2, \mathrm{Hex} / \mathrm{DCM}$ from 100 to $20: 80$ ) to obtain a yellow powder $(0.8534 \%)$. $1 \mathrm{H} \mathrm{NMR}\left(500 \mathrm{MHz}\right.$, benzene- $\left.\mathrm{d}_{6}\right)$

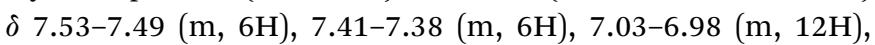
6.98-6.94 (m, 6H), 6.82-6.78 (m, 6H), 6.70-6.67 (m, 12H), 3.28 (s, 18H). 13C NMR (126 MHz, benzene-d $)_{6} \delta$ 156.55, 148.89, 146.37, 140.37, 132.60, 127.97, 127.07, 127.57, 124.01, 119.61, $118.75,114.87,90.37,88.66,54.66$. Anal. calcd for $\mathrm{C}_{84} \mathrm{H}_{66} \mathrm{~N}_{4} \mathrm{O}_{6}$ : C, 82.20; H, 5.42; N, 4.56; found: C, 82.12; H, 5.37; N, 4.63: [M]+ found 1227.50 .

STR0. A mixture of tris-4-bromo(2,2' $: 6^{\prime} 2^{\prime \prime}$-dioxytriphenylamine (0.98 mmol, $0.5 \mathrm{~g})$, (PPh3)2PdCl2 (0.10 mmol, $72 \mathrm{mg}$ ), CuI (4 mg), 4-ethynyl- $N, N$-bis(4-methoxyphenyl)aniline (3.43 mmol, $1.98 \mathrm{~g})$ and piperidine $(30 \mathrm{~mL})$ in toluene $(20 \mathrm{~mL})$ were degassed by freeze-pump thaw and mixture stirred for $72 \mathrm{~h}$ nitrogen atmosphere. The reaction was stopped by the addition $20 \mathrm{~mL}$ of $\mathrm{NH}_{4} \mathrm{Cl}$ and the product extracted with DCM. The crude was passed through a quick silica plug in DCM and the product purified by column chromatography (SiO2, Hex/DCM from $50: 50$ to $10: 90)$ to obtain a pale yellow powder $(0.35 \mathrm{~g} 28 \%)$. 1H NMR (500 MHz, acetone-d $\left.{ }_{6}\right) \delta 7.44(\mathrm{~d}, J=8.4 \mathrm{~Hz}, 2 \mathrm{H}), 7.34-$ $7.30(\mathrm{~m}, 6 \mathrm{H}), 7.19$ (dd, $J=8.4,1.9 \mathrm{~Hz}, 2 \mathrm{H}), 7.14-7.09(\mathrm{~m}, 12 \mathrm{H})$, $7.06(\mathrm{~d}, J=1.9 \mathrm{~Hz}, 2 \mathrm{H}), 6.98-6.93(\mathrm{~m}, 12 \mathrm{H}), 6.81-6.77(\mathrm{~m}, 6 \mathrm{H})$, $6.71(\mathrm{~s}, 2 \mathrm{H}), 3.81(\mathrm{~d}, J=0.8 \mathrm{~Hz}, 18 \mathrm{H})$. Anal. calcd for $\mathrm{C}_{84} \mathrm{H}_{62} \mathrm{~N}_{4} \mathrm{O}_{6}$ : C, 80.36; H, 4.98; N, 4.46; found: C, 80.22; $\mathrm{H}$, 4.92; N, 4.61: $[\mathrm{M}]+$ found 1255.46 .

\subsection{Optical characterization}

Solution UV-Visible absorption spectra were recorded using a Jasco V-670 UV/Vis/NIR spectrometer controlled with SpectraManager software. Photoluminescence (PL) spectra were recorded with a Fluoromax-3 fluorimeter controlled by ISAMain software. All samples were measured in a $1 \mathrm{~cm}$ cell at room temperature in dichloromethane as solvent. 


\subsection{Electrochemical characterization}

All square-wave voltammetry measurements were carried out in freshly distilled $\mathrm{CH}_{2} \mathrm{Cl}_{2}$ using $0.3 \mathrm{M}$ [TBA] $\left[\mathrm{BF}_{4}\right]$ electrolyte in a three-electrode system with each solution being purged with $\mathrm{N}_{2}$ prior to measurement. The working electrode was a Pt disk, the reference electrode was $\mathrm{Ag} / \mathrm{AgCl}$, and the counter electrode was a Pt rod. All measurements were made at room temperature using a $\mu$ UTOLAB Type III potentiostat, driven by the electrochemical software GPES. Ferrocene was used as the internal standard in each measurement.

\subsection{Thermal characterization}

Differential scanning calorimetry (DSC) was performed on NETZSCH STA $449 \mathrm{~F} 1$ at a scan rate of $5 \mathrm{~K}$ min -1 under a nitrogen atmosphere in DSC/TG aluminium pan. The measurement range was $25{ }^{\circ} \mathrm{C}$ to $250{ }^{\circ} \mathrm{C}$.

\subsection{Computational details}

All calculations were carried out using the Gaussian 09 program with Lee Yang-Parr correlation functional (B3LYP). All atoms were described by the $6-31 \mathrm{G}(\mathrm{d})$ basis set. All structures were input and processed through the Avogadro software package.

\subsection{Charge transport properties}

The device structure for hole only devices was $\mathrm{Si} / \mathrm{SiO}_{2} / \mathrm{Au} /$ PEDOT:PSS (Al 4083)/HTL/ $\mathrm{MoO}_{3} / \mathrm{Ag}$. Si/SiO ${ }_{2}(200 \mathrm{~nm})$ were thoroughly cleaned by sonication in Acetone, IPA before boiling in Piranha solution at $90{ }^{\circ} \mathrm{C}\left(\mathrm{H}_{2} \mathrm{O}\right.$ (5): $\mathrm{NH}_{4} \mathrm{OH}$ (1): $\mathrm{H}_{2} \mathrm{O}_{2}$ (1)). $50 \mathrm{~nm}$ thick $\mathrm{Au}$ pads were thermally evaporated. These substrates were treated with air plasma for 5 minutes.

A filtered $(0.45 \mu \mathrm{m} \quad \mathrm{PTFE})$ solution of $\operatorname{poly}(3,4-$ ethylendioxythiophene)-poly(styrene sulfonate) (PEDOT:PSS Al 4083) was spin-coated on top of $\mathrm{Si} / \mathrm{SiO}_{2} / \mathrm{Au}$ substrate at $4500 \mathrm{rpm}$ for $30 \mathrm{~s}$. The HTMs were spin-coated at $1000 \mathrm{rpm}$ onto PEDOT:PSS coated substrates from chlorobenzene solution (40 $\mathrm{mg} \mathrm{mL}^{-1}$, filtered $0.45 \mu \mathrm{m}$ PTFE). The thickness of the HTLS films $(150 \mathrm{~nm})$ were estimated from AFM. Silver (Ag) was used as a top electrode. An interlayer of $\mathrm{MoO}_{3}$ was deposited between the HTL and the top electrode. Mobilities were calculated using Mott-Gurney's or Child's law:

$$
\mu=\frac{8 J L^{3}}{V^{2} 9 \varepsilon_{0} \varepsilon_{\mathrm{r}}}
$$

where $J$ is the current density, $\varepsilon_{\mathrm{r}}$ is the material's dielectric constant ( $\sim 3.5$ for most organic semiconductors), $\varepsilon_{0}$ is the permittivity of free space, $V$ is the applied voltage and $L$ is the thickness of the HTLs.

\subsection{Perovskite solar cells and characterisation}

Etched FTO glass substrates (NSG Pilkington, TEC7) were cleaned sequentially in detergent, deionised water, acetone and ethanol before undergoing 10 minutes of $\mathrm{O}_{2}$ plasma treatment. A compact $\mathrm{TiO}_{2}$ layer was deposited on the glass substrates through spray pyrolysis of a $0.2 \mathrm{M}$ solution of titanium diisopropoxide bis(acetylacetonate) in isopropanol at $450{ }^{\circ} \mathrm{C}$. Upon cooling, a mesoporous layer of $\mathrm{TiO}_{2}$ nanoparticles was spincoated from a 2:7 wt suspension of Dyesol 30NR-D paste in ethanol (4,500 rpm for 30 seconds), followed by sintering at

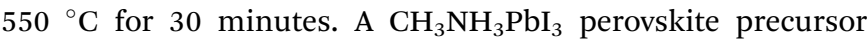
solution was prepared by dissolving $576 \mathrm{mg} \mathrm{PbI}_{2}$, and $199 \mathrm{mg}$ $\mathrm{CH}_{3} \mathrm{NH}_{3} \mathrm{I}$ in a $4: 1 \mathrm{vol}$ solution of DMF : DMSO. $100 \mu \mathrm{L}$ of the perovskite precursor solution was deposited onto the $\mathrm{TiO}_{2}$ films and spin-coated at $4000 \mathrm{rpm}$ for 30 seconds, with $200 \mu \mathrm{L}$ of ethyl acetate dripped onto the spinning substrate 10 seconds prior to the end of the spin-coating process. Perovskite films were annealed at $100{ }^{\circ} \mathrm{C}$ for 10 minutes. A solution in chlorobenzene for each HTM (80 mg mL $\mathrm{mL}^{-1}$ ) was prepared with dopants including bis(trifluoromethylsulfonyl)imide lithium salt (LiTFSI) $\left(20 \mu \mathrm{L} \mathrm{mL}^{-1}\right.$ of a $520 \mathrm{mg} \mathrm{mL}^{-1}$ solution in acetonitrile), 4-tert-butylpyridine $\left(t \mathrm{BP}, 30 \mu \mathrm{L} \mathrm{mL^{-1 } )}\right.$ and tris(2-(1H-pyrazol-1yl)-4-tertbutylpyridine)-cobalt(III) tris(bis(trifluoromethylsulfonyl)imide) (FK209, $10 \mu \mathrm{L} \mathrm{mL}^{-1}$ of a $300 \mathrm{mg} \mathrm{mL} \mathrm{m}^{-1}$ solution in acetonitrile). The HTM solution was spin-coated onto perovskite films at $4000 \mathrm{rpm}$ for 30 seconds before $80 \mathrm{~nm}$ thick $\mathrm{Au}$ contacts were thermally evaporated onto devices. Current-voltage measurements were performed using an AAA-rated solar simulator (Oriel Sol3A) calibrated against a KG5-filtered reference diode (Oriel 91150-KG5). Solar cells were masked to $0.1 \mathrm{~cm}^{2}$ and scanned both from forward to reverse bias and vice versa at $100 \mathrm{mV} \mathrm{s}^{-1}$. The external quantum efficiency of solar cells was measured using a Enlitech QE-R system with monochromated light chopped at $210 \mathrm{~Hz}$, at $10 \mathrm{~nm}$ intervals. calibrated against a NIST-traceble silicon reference cell.

\section{Conflicts of interest}

There are no conflicts of interest to declare.

\section{Acknowledgements}

RFP thanks CONACYT, Mexico for a PhD studentship. We thank EPSRC EP/H040218/1 and EP/M023532/1 for financial support and the Royal Society for supporting the UK-Canada collaboration. DFP, MRN and YZ acknowledge support from NSERC.

\section{Notes and references}

1 A. Kojima, K. Teshima, Y. Shirai and T. Miyasaka, J. Am. Chem. Soc., 2009, 131, 6050-6051.

2 NREL, Best Research Cell Efficiency Chart, 2019.

3 S. Kazim, M. K. Nazeeruddin, M. Grätzel and S. Ahmad, Angew. Chem., Int. Ed., 2014, 53, 2812-2824.

4 M. Saliba, J. P. Correa-Baena, M. Grätzel, A. Hagfeldt and A. Abate, Angew. Chem., Int. Ed., 2018, 57, 2554-2569.

5 S. Ameen, M. A. Rub, S. A. Kosa, K. A. Alamry, M. S. Akhtar, H. S. Shin, H. K. Seo, A. M. Asiri and M. K. Nazeeruddin, ChemSusChem, 2016, 9, 10-27.

6 H. D. Pham, L. Xianqiang, W. Li, S. Manzhos, A. K. K. Kyaw and P. Sonar, Energy Environ. Sci., 2019, 12, 1177-1209.

7 W. Tress, N. Marinova, O. Inganas, M. K. Nazeeruddin, S. M. Zakeeruddin and M. Graetzel, in IEEE 40th 
Photovoltaic Specialist Conference (PVSC), IEEE, 2014, pp. 1563-1566.

8 M. L. Petrus, A. Music, A. C. Closs, J. C. Bijleveld, M. T. Sirtl, Y. Hu, T. J. Dingemans, T. Bein and P. Docampo, J. Mater. Chem. A, 2017, 5, 25200-25210.

9 Y.-K. Wang, Z.-C. Yuan, G.-Z. Shi, Y.-X. Li, Q. Li, F. Hui, B.-Q. Sun, Z.-Q. Jiang and L.-S. Liao, Adv. Funct. Mater., 2016, 26, 1375-1381.

10 Y. L. Xu, W. L. Ding and Z. Z. Sun, Nanoscale, 2018, 10, 20329-20338.

11 J. Urieta-Mora, I. García-Benito, A. Molina-Ontoria and N. Martín, Chem. Soc. Rev., 2018, 47, 8541-8571.

12 V. E. Madhavan, I. Zimmermann, C. Roldán-Carmona, G. Grancini, M. Buffiere, A. Belaidi and M. K. Nazeeruddin, ACS Energy Lett., 2016, 1, 1112-1117.

13 M. Lv, J. Zhu, Y. Huang, Y. Li, Z. Shao, Y. Xu and S. Dai, ACS Appl. Mater. Interfaces, 2015, 7, 17482-17488.

14 J. A. Christians, R. C. M. Fung and P. V. Kamat, J. Am. Chem. Soc., 2014, 136, 758-764.

15 M. Daskeviciene, S. Paek, Z. Wang, T. Malinauskas, G. Jokubauskaite, K. Rakstys, K. T. Cho, A. Magomedov, V. Jankauskas, S. Ahmad, H. J. Snaith, V. Getautis and M. K. Nazeeruddin, Nano Energy, 2017, 32, 551-557.

16 M. Nazim, S. Ameen, M. S. Akhtar, M. Khaja Nazeeruddin and H. S. Shin, Sol. Energy Mater. Sol. Cells, 2018, 180, 334-342.

17 C. H. Teh, R. Daik, E. L. Lim, C. C. Yap, M. A. Ibrahim, N. A. Ludin, K. Sopian and M. A. Mat Teridi, J. Mater. Chem. A, 2016, 4, 15788-15822.

18 Z. Yu, Y. Zhang, X. Jiang, X. Li, J. Lai, M. Hu, M. Elawad, G. G. Gurzadyan, X. Yang and L. Sun, RSC Adv., 2017, 7, 27189-27197.

19 H. C. Liao, T. L. D. Tam, P. Guo, Y. Wu, E. F. Manley, W. Huang, N. Zhou, C. M. M. Soe, B. Wang, M. R. Wasielewski, L. X. Chen, M. G. Kanatzidis, A. Facchetti, R. P. H. Chang and T. J. Marks, Adv. Energy Mater., 2016, 6, 1600502.

20 S. Valero, S. Collavini, S. F. Völker, M. Saliba, W. R. Tress, S. M. Zakeeruddin, M. Grätzel and J. L. Delgado, Macromolecules, 2019, 52, 2243-2254.

21 U. Bach, D. Lupo, P. Comte, J. E. Moser, F. Weissörtel, J. Salbeck, H. Spreitzer and M. Grätzel, Nature, 1998, 395, 583-585.

22 M. M. Lee, J. Teuscher, T. Miyasaka, T. N. Murakami and H. J. Snaith, Science, 2012, 338, 643-647.

23 W. S. Yang, B. W. Park, E. H. Jung, N. J. Jeon, Y. C. Kim, D. U. Lee, S. S. Shin, J. Seo, E. K. Kim, J. H. Noh and S. Il Seok, Science, 2017, 356, 1376-1379.

24 S. Ryu, J. H. Noh, N. J. Jeon, Y. Chan Kim, W. S. Yang, J. Seo and S. Il Seok, Energy Environ. Sci., 2014, 7, 2614-2618.

25 A. K. Jena, Y. Numata, M. Ikegami and T. Miyasaka, J. Mater. Chem. A, 2018, 6, 2219-2230.

26 K. Domanski, J. P. Correa-Baena, N. Mine, M. K. Nazeeruddin, A. Abate, M. Saliba, W. Tress, A. Hagfeldt and M. Grätzel, ACS Nano, 2016, 10, 6306-6314.

27 I. Mesquita, L. Andrade and A. Mendes, ChemSusChem, 2019, 12, 2186-2194.
28 R. S. Sanchez and E. Mas-Marza, Sol. Energy Mater. Sol. Cells, 2016, 158, 189-194.

29 X. Zhao, H. S. Kim, J. Y. Seo and N. G. Park, ACS Appl. Mater. Interfaces, 2017, 9, 7148-7153.

30 PTAA - Poly[bis(4-phenyl)(2,4,6-trimethylphenyl)amine] | Sigma-Aldrich, https:/www.sigmaaldrich.com/catalog/ product/aldrich/702471 lang $=$ en\&region $=\mathrm{GB}$, accessed 11 August 2019.

31 J. Wang, K. Liu, L. Ma and X. Zhan, Chem. Rev., 2016, 116, 14675-14725.

32 P. Agarwala and D. Kabra, J. Mater. Chem. A, 2017, 5, 13481373.

33 Y. Kim, E. H. Jung, G. Kim, D. Kim, B. J. Kim and J. Seo, Adv. Energy Mater., 2018, 8, 1801668.

34 H. D. Pham, L. Gil-Escrig, K. Feron, S. Manzhos, S. Albrecht, H. J. Bolink and P. Sonar, J. Mater. Chem. A, 2019, 7, 1250712517.

35 M. Ulfa, T. Zhu, F. Goubard and T. Pauporté, J. Mater. Chem. A, 2018, 6, 13350-13358.

36 K. Choi, J. Lee, H. Il Kim, C. W. Park, G. W. Kim, H. Choi, S. Park, S. A. Park and T. Park, Energy Environ. Sci., 2018, 11, 3238-3247.

37 G. W. Kim, G. Kang, M. Malekshahi Byranvand, G. Y. Lee and T. Park, ACS Appl. Mater. Interfaces, 2017, 9, 27720-27726.

38 C. C. Boyd, R. Cheacharoen, T. Leijtens and M. D. McGehee, Chem. Rev., 2019, 119, 3418-3451.

39 Y. Ko, Y. Kim, C. Lee, Y. Kim and Y. Jun, ACS Appl. Mater. Interfaces, 2018, 10, 11633-11641.

40 A. Krishna and A. C. Grimsdale, J. Mater. Chem. A, 2017, 5, 16446-16466.

41 M. Thelakkat, Macromol. Mater. Eng., 2002, 287, 442-461.

42 A. L. Kanibolotsky, I. F. Perepichka and P. J. Skabara, Chem. Soc. Rev., 2010, 39, 2695-2728.

43 S. Paek, N. Cho, S. Cho, J. K. Lee and J. Ko, Org. Lett., 2012, 14, 6326-6329.

44 M. Sonntag, K. Kreger, D. Hanft, P. Strohriegl, S. Setayesh and D. De Leeuw, Chem. Mater., 2005, 17, 3031-3039.

45 K. R. J. Thomas, J. T. Lin, Y. T. Tao and C. W. Ko, Chem. Mater., 2002, 14, 1354-1361.

46 S. Paek, H. Choi, J. Sim, K. Song, J. K. Lee and J. Ko, J. Phys. Chem. C, 2014, 118, 27193-27200.

47 H. Choi, S. Park, S. Paek, P. Ekanayake, M. K. Nazeeruddin and J. Ko, J. Mater. Chem. A, 2014, 2, 19136-19140.

48 F. Zhang, X. Zhao, C. Yi, D. Bi, X. Bi, P. Wei, X. Liu, S. Wang, X. Li, S. M. Zakeeruddin and M. Grätzel, Dyes Pigm., 2017, 136, 273-277.

49 K. Do, H. Choi, K. Lim, H. Jo, J. W. Cho, M. K. Nazeeruddin and J. Ko, Chem. Commun., 2014, 50, 10971-10974.

50 A. Wakamiya, H. Nishimura, T. Fukushima, F. Suzuki, A. Saeki, S. Seki, I. Osaka, T. Sasamori, M. Murata, Y. Murata and H. Kaji, Angew. Chem., Int. Ed., 2014, 53, 5800-5804.

51 R. Fuentes Pineda, J. Troughton, M. Planells, I. SanchezMolina Santos, F. Muhith, G. S. Nichol, S. Haque, T. Watson and N. Robertson, Phys. Chem. Chem. Phys., 2018, 20, 1252-1260. 
52 G. Wu, G. Zhao, C. He, J. Zhang, Q. He, X. Chen and Y. Li, Sol. Energy Mater. Sol. Cells, 2009, 93, 108-113.

53 M. Schilz and H. Plenio, J. Org. Chem., 2012, 77, 2798-2807. 54 R. Chinchilla and C. Nájera, Chem. Rev., 2007, 107, 874-922.

55 M. Kuratsu, M. Kozaki and K. Okada, Angew. Chem., Int. Ed., 2005, 44, 4056-4058.

56 S. Suzuki, A. Nagata, M. Kuratsu, M. Kozaki, R. Tanaka, D. Shiomi, K. Sugisaki, K. Toyota, K. Sato, T. Takui and K. Okada, Angew. Chem., Int. Ed., 2012, 51, 3193-3197.

57 M. Kuratsu, M. Kozaki and K. Okada, Chem. Lett., 2004, 33, 1174-1175.

58 C. M. Cardona, W. Li, A. E. Kaifer, D. Stockdale and G. C. Bazan, Adv. Mater., 2011, 23, 2367-2371.

59 M. Planells, A. Abate, D. J. Hollman, S. D. Stranks, V. Bharti, J. Gaur, D. Mohanty, S. Chand, H. J. Snaith and N. Robertson, J. Mater. Chem. A, 2013, 1, 6949-6960.

60 Y. Song, S. Lv, X. Liu, X. Li, S. Wang, H. Wei, D. Li, Y. Xiao and Q. Meng, Chem. Commun., 2014, 50, 15239-15242.

61 J. C. Blakesley, F. A. Castro, W. Kylberg, G. F. A. Dibb, C. Arantes, R. Valaski, M. Cremona, J. S. Kim and J. S. Kim, Org. Electron., 2014, 15, 1263-1272.

62 T. Leijtens, I. K. Ding, T. Giovenzana, J. T. Bloking, M. D. McGehee and A. Sellinger, ACS Nano, 2012, 6, 14551462.

63 Y. Liu, Z. Hong, Q. Chen, H. Chen, W. H. Chang, T. Bin Song and Y. Yang, Adv. Mater., 2016, 28, 440-446.

64 H. J. Snaith and M. Grätzel, Appl. Phys. Lett., 2006, 89, 262114.

65 W. H. Nguyen, C. D. Bailie, E. L. Unger and M. D. McGehee, J. Am. Chem. Soc., 2014, 136, 10996-11001.

66 A. Abate, D. R. Staff, D. J. Hollman, H. J. Snaith and A. B. Walker, Phys. Chem. Chem. Phys., 2014, 16, 1132-1138.

67 S. Wang, Z. Huang, X. Wang, Y. Li, M. Günther, S. Valenzuela, P. Parikh, A. Cabreros, W. Xiong and Y. S. Meng, J. Am. Chem. Soc., 2018, 140, 16720-16730.
68 A. Abate, T. Leijtens, S. Pathak, J. Teuscher, R. Avolio, M. E. Errico, J. Kirkpatrik, J. M. Ball, P. Docampo, I. McPherson and H. J. Snaith, Phys. Chem. Chem. Phys., 2013, 15, 2572-2579.

69 Q. Wang, Phys. Chem. Chem. Phys., 2018, 20, 10114-10120.

70 U. B. Cappel, T. Daeneke and U. Bach, Nano Lett., 2012, 12, 4925-4931.

71 E. J. Juarez-Perez, M. R. Leyden, S. Wang, L. K. Ono, Z. Hawash and Y. Qi, Chem. Mater., 2016, 28, 5702-5709.

72 T. H. Schloemer, J. A. Christians, J. M. Luther and A. Sellinger, Chem. Sci., 2019, 10, 1904-1935.

73 R. A. Belisle, P. Jain, R. Prasanna, T. Leijtens and M. D. McGehee, ACS Energy Lett., 2016, 1, 556-560.

74 M. Stolterfoht, P. Caprioglio, C. M. Wolff, J. A. Márquez, J. Nordmann, S. Zhang, D. Rothhardt, U. Hörmann, Y. Amir, A. Redinger, L. Kegelmann, F. Zu, S. Albrecht, N. Koch, T. Kirchartz, M. Saliba, T. Unold and D. Neher, Energy Environ. Sci., 2019, 12, 2778-2788.

75 I. Gelmetti, N. F. Montcada, A. Pérez-Rodríguez, E. Barrena, C. Ocal, I. García-Benito, A. Molina-Ontoria, N. Martín, A. Vidal-Ferran and E. Palomares, Energy Environ. Sci., 2019, 12, 1309-1316.

76 B. Dänekamp, N. Droseros, D. Tsokkou, V. Brehm, P. P. Boix, M. Sessolo, N. Banerji and H. J. Bolink, J. Mater. Chem. C, 2019, 7, 523-527.

77 H. Xi, S. Tang, X. Ma, J. Chang, D. Chen, Z. Lin, P. Zhong, H. Wang and C. Zhang, ACS Omega, 2017, 2, 326-336.

78 N. J. Jeon, H. Na, E. H. Jung, T. Y. Yang, Y. G. Lee, G. Kim, H. W. Shin, S. Il Seok, J. Lee and J. Seo, Nat. Energy, 2018, 3, 682-689.

79 X. Liu, X. Ding, Y. Ren, Y. Yang, Y. Ding, X. Liu, A. Alsaedi, T. Hayat, J. Yao and S. Dai, J. Mater. Chem. C, 2018, 6, 12912-12918. 